\title{
Risk Management Strategies and the Role of Social Context: A Comparative Study
}

\author{
E. Fragouli ${ }^{1, *}$, D. Hutcheon ${ }^{1}, \&$ J. Faryna ${ }^{1}$ \\ ${ }^{1}$ University of Dundee, UK \\ *Corresponding author: University of Dundee, UK. E-mail: e.fragouli@dundee.ac.uk
}

Received: December 8, 2017 Accepted: December 27, 2017 Published: February 2, 2018

doi: 10.5296/erm.v4i1.12582ＵRL: https://doi.org/10.5296/erm.v4i1.12582

\begin{abstract}
Researchers have been suggesting that there is a need to examine the wider social context and its role in influencing flood risk management strategies; this has also been joined by a call for further research into the risks of increased rainfall as part of overall climate change. In response to these calls this research study examines the case studies of two pluvial, meaning of or caused by rainfall, flood events; the Calgary, Canada floods of 2013 and the Montrose, Scotland floods of 2016. These events were considered to be 1 in 100 year low probability scenarios and caused significant disruption to the affected areas. The study focuses on the examination into the social context of such events; by examining the risk perceptions before the event, the flood management strategies used and the social impact of the events it was possible to gain insight into the wider picture of pluvial flooding. The analysis of the cases demonstrated that the perceptions of the events were low, due to the unusual nature of the events, but the forecasting of a flood and the issuing of warnings helped to reduce the impact and predict the areas that were most likely to be affected. It has also highlighted the importance of setting common goals, and engaging with, all the necessary stakeholders to improve the effectiveness of strategies and responses. The study concludes by indicating issues that may be of interest to decision makers and researchers in the field of risk management.
\end{abstract}

Keywords: risk management, strategy, social, stakeholders 


\section{Introduction}

We are all aware of the increasing focus on environmental issues in the organisational, political and social dimensions of the current era. There has been a large increase in extreme weather events across the globe with varying levels of potential risks depending on the geographical location and the responses taken to deal with the potential risks. This study will focus on two cases of extreme pluvial (caused by rain) river flooding events and compare how the social context in the areas they occurred in have affected the flood risk management strategies that were used. The cases selected were the 2013 flood in Calgary, Canada and the 2016 flood in Montrose, Scotland; they were both caused by extreme rainfall over a short time period and considered to be unusual for existing weather trends.

There is no clear indication that the rise in flooding events is part of wider climate change, the reasons vary but increased rainfall over shorter periods is often cited as a significant contributing factor. From the examination of the literature it was shown that the social context could play a large part in the success and co-ordination of flood management strategies, requiring further research, and the suitability of case study based research to examine the social context. The cases are both pluvial river based flooding events with a low probability, such as once in 100 years, and occurred in areas that have comparable infrastructure, local and national Governement, environmental agencies and social attitudes towards environmental concerns. The wider social context of each event was examined to identify the relevant factors to this research.

The specific aim of this research is to compare the social context, and flood management strategies, of two comparable pluvial flood events. In order to examine this larger issue the analysis of the data collected focuses on three smaller areas; these were driven by the review of the literature available and are stated below:

- Due to the extreme nature, and low probability, of such events what were the risk perceptions of the society before the events?

- What were the strategies in place for such events and who was responsible for their delivery?

- What was the impact of the events and had the strategies been successful in their aims?

In the examination of these areas it is possible to build a picture of the social context that can assist with understanding how stakeholder perceptions, a lack of co-ordinated strategic aims, community resilience and social factors of each location may have influenced the flood risk management of the two cases. As the social context effects are not fully understood, and researchers are calling for it to be examined, this study represents a first step towards explaining this gap in the existing research literature.

The following sections discuss how the review of existing literature identified the need to examine the social context and its effects on flood management strategies before discussing the methodology of the study and how it was applied. This is then followed by an analysis of 
the case studies and a discussion on their relevant points.

\section{Risk Perception \& Risk Management}

\subsection{Risk Perception and Awareness of Extreme Flooding Events}

The recent work of Birkholz et al (2014) examined the history of risk perception research and the growing fissure between rationalist and constructivist approaches. In their review they were able to broadly categorise the insights of both approaches advocating the benefits of future research being more constructivist in approach (Birkholz et al 2014). They demonstrate that more recent research has offered improved insight by examining risk as a social construction where research focuses on the societal factors that influence risk estimation (Birkholz et al 2014). In their review they show that this approach calls for the "critical analysis of the context of major accidents and disasters" and should also examine "the role of organisations and governments in shaping risk perceptions in societies" (Birkholz et al 2014, page 16). It is also suggested that "there is a need for a re-invigoration of flood risk perception research, in order to deliver a more comprehensive understanding of how risk perceptions influence the vulnerability, capacity and resilience of individuals and communities in the face of flooding" (Birkholz et al 2014, page 18). This is suggestive of the suitability of the use of case studies in order to gain an insight into the full social context of a flooding event as well as the role of various Government and environmental agencies in shaping risk perceptions.

\subsection{Flood Risk Management and Community Resilience}

The recent work of Rouillard et al (2015) examined the change of policy making towards a more 'catchment scale' approach to flood management, this style of management aims to reduce urban flooding through rural land use change. This allows for Local Authorities to engage with stakeholders, such as local landowners, to adopt rural land changes to reduce flood risks. Their research examined the River Tweed basin that lies on the Scottish/English border allowing for a comparison of local policy implementation from both sides of the border. In the results of their study they identify that there is a divide between the aims of 'catchment scale' flood management and the agencies involved as "despite regionally specific plans, the main actors involved in implementing catchment FRM are organisations with a national remit who also work within national guidelines and plans" (Rouillard et al 2015, page 158). They suggest that future research should "examine more specifically the role of devolution in promoting catchment FRM, in particular examining cases where FRM is not promoted as a local issue" (Rouillard et al 2015, page 162). This is similar to the earlier work of Kenyon (2007) who examined Scottish flood risk management options. At the national level the Scottish Government aims to "provide the maximum possible social and economic resilience against flooding, by protecting and working with the environment, in a way that is fair and affordable both now and in the future" (Kenyon 2007, page 79). Attitudes amongst the stakeholders studied showed a preference towards "regeneration or planting of native woodland to other flood management options, and least preferred building flood walls 
and embankments" (Kenyon 2007, page 80).

The work of Mann and Wolfe (2016) examined the perceptions and resilience of urban flooding in Toronto, Canada after the July 2013 floods where "data indicated that $126 \mathrm{~mm}$ of rainfall" (Mann and Wolfe 2016, page 2658) fell in a two hour period arriving at the same previously identified point of social context influencing flood management. They found that "residents' societal beliefs about flooding play a major role in guiding flood management strategies" (Mann and Wolfe 2016, page 2651) as well as the similar disconnection between society and agencies on the risk of flooding indicating that "flooding, on the other hand, may not be viewed with such a collective mind-set" (Mann and Wolfe 2016, page 2661) which they attribute to the social context where the "responsibility may be seen as falling on municipal government for stormwater control" (Mann and Wolfe 2016, page 2661). This point is developed further by the work of Whitfield and Pomeroy (2016) whose work examined the floods around the Calgary over a period of time said it presents an opportunity to examine the flexibility of modern flood management in the area as it is not suited to coping with unexpected events. They state that for "flood-generating processes that change in proportion over time, existing methods are clearly inadequate and unreliable" (Whitfield and Pomeroy 2016, page 4670). This shows that there are already some factors regarding the social context present in both Canada and Scotland in relation to the implementation and co-ordination of the management of river based flash flooding events suggesting that the social context is in need of further research.

\subsection{Evaluating Flood Risk Management Strategies}

The recent work of Brudler et al (2016) examined pluvial flooding and the implementation of stormwater management techniques, pluvial meaning of or caused by rain. This work separated flooding events by a three point approach based on their chronological likelihood, or return period; $1^{\text {st }}$ domain events are 0.2 years, $2^{\text {nd }}$ domain are 10 years and $3^{\text {rd }}$ domain are 100 years (Brudler et al). In response to growing climate change Copenhagen have developed a cloudburst management plan which involves combining sewer drainage, surface rainwater routing and underground pipes to meet flood safety requirements for $3^{\text {rd }}$ domain events (Brudler et al 2016). The research concluded that the use of the three point approach during the flood management planning process was beneficial as it "facilitates communication between stakeholders with different priorities and allows one to quantify trade-offs between environmental sustainability and flood safety" (Brudler et al 2016, page 403). The findings of this study repeat the suggestion that the synthesis of all stakeholders, or the social context, at all levels is necessary for the success of an effective flood management plan.

The review of recent literature discussed highlights the suitability of using a case study based approach, already widespread in the research, to examine the wider social context and its effects on the successful implementation of flood management strategies. As agencies tend to have a national goal but interact on the local level there are often inconsistencies in the co-ordination of flood management at this level. 


\section{Methodology}

This research was conducted using an interpretive approach, examining qualitative secondary data sources of two cases of urban flooding events. This methodology choice allowed for the collection of data regarding the impact of the events, not often felt until a short time after the events have occurred, and examine if there had been any changes to the perception and management of such events. The full statement of the reasons for adopting this particular methodological approach are discussed in the following sections in more detail.

\subsection{Methodology Design}

The design of a suitable methodology for examining this topic is necessary as a methodology aims to provide " $a$ way of examining social phenomena from which particular understandings of these phenomena can be gained and explanations attempted" (Saunders et al 2009, page 149). As this study will be using secondary data to examine each flooding case it is best to adopt an interpretative approach, this allowed for a smaller sample size, from a naturally occurring location, to be used; it also allows for the increased validity of the findings to be generalised between similar locations (Collis and Hussey 2009). The use of only secondary data sources for the research is acceptable as "research data can be secondary data (...), primary data (...) or both" (Collis and Hussey 2009, page 221) and for student research there is also the point that there is often "less scope for primary research and therefore the literature review will form a more substantial part of the report" (Collis and Hussey 2009, page 299). With this point in mind as this research is examining two cases, those being Montrose in Scotland and Calgary in Canada, the literature review was conducted with research, where available, from Scotland and Canada in order to provide further focus to the research question. This was combined with information from peer reviewed journals to examine theoretical research as well in order to gain as accurate an insight as possible.

The use of case studies for this research is beneficial as case study research allows researchers to "confirm and deepen understanding by using multiple sources all focusing on the same process/event" (Woodside 2010, page 1). The case study method is also endorsed by other researchers as the most suitable method as it can offer "in-depth understanding to current and highly relevant real life problems in an interrelated context" (Rambaruth 2012, page 252) such as the political, economic, social and cultural impacts of such events. Having examined the methodologies of other research in the same area there is widespread use of case studies in risk and environmental research already; works such as Kajenthira et al (2010) and Shao-Hong et al (2012) used countries as the cases in their research. For these reasons it was chosen to use a case study approach for the secondary data collection.

Also, internet searches provided information in a varying range of media and format, such as News websites, YouTube videos, environmental agencies websites, meteorological agencies websites and Local Authority websites. The information gained from these searches was sorted by the location of the case study events and then thematically analysed to decide its relevance to reduce the sources before further analysis. 


\subsection{Limitations}

This study is limited by its short time scale, which made it possible to compare only two case studies, whereas comparing several case studies may have produced more comparatively generic results overall. The journalistic nature of some of the sources was a factor, as was the social mobile phone and drone footage available on YouTube, as the information can be opinion biased but care was taken to stick to factual elements of the sources. As this study was using only secondary data there are no significant ethical considerations other than to ensure the information used, and quoted, was appropriately referenced in order to credit the original authors.

\section{Case Studies}

This section provides a summary of each of the events, and the analysis of the relevant points of each case study, separately so that a comparison of the events becomes possible. As stated in the methodology the cases were selected due to the similarity of the social context, the cause of the flood, the low probability of the events, both being river based and both having occurred within the last five years.

\subsection{Calgary, Canada. 2013}

In the summer of 2013 the rainfall around the Alberta region of Canada became unseasonably high; the city of Calgary is the only city in Canada that sits at the confluence of two rivers (Nielson 2015). In 2013 "heavy rains and mountain snow melt from mid-May to mid-July combined with steep, rocky topography and limited lake and reservoir storage to make the Bow and Elbow watersheds vulnerable to rapid and intense flooding" (Nielson 2015, page 143). The flooding was considered " $a 1$ in 100 year event when the rivers reached the City of Calgary" (Nielson 2015, page 144) with the water flowing through the city at a rate comparable to the Niagara Falls resulting in nearly \$6 Billion dollars of damages to public and private property (Nielson 2015).

\subsubsection{Risk Perception of the Event}

The citizens of Southern Alberta are familiar with high water levels and plenty of rain in June, however their perceptions of a major flood disaster occurring is seen to be rare. On June $20^{\text {th }}$ 2013, Southern Alberta experienced one of the largest flood disasters ever recorded. Geologist, Dr. Osborn explains that the last major flood to occur at that scale was in 1932 so consequently the citizens have lost the concept and perception that the city has a flood hazard (YouTube 2013). Even the Mayor of Calgary was notified of the increasing waters and was unconcerned stating, "It is June and it happens every year." Many of the citizens describe being surprised by the amount of rain pouring down in the early stages of the storm and how fast the river was moving (YouTube 2013). Calgarians underestimated the power of the rivers even though they experienced a major flood in June of 2005, which caused flood damage to 40,000 homes, and approximately 1,500 Calgarians were evacuated, however the flood of 2013 would be the most destructive flood in the history of the province (Floodstory, 2014). 


\subsubsection{Flood Risk Management Strategy}

The mayor of Calgary made the first strategic decision to authorise a state of local emergency (YouTube 2014). Thus, granting the Calgary Emergency Management Agency (CEMA) authorisation to co-ordinate the city's response to the flood, overseeing the efforts of 29 Business Units, 12 external members, seven invited partners and roughly 7,000 City staff who aided in emergency response and initial recovery activities (EM2013-0822). In total 32 local states of emergency and 28 emergency operations centres were activated in Southern Alberta (Floodstory 2014). A key strategy in planning for flood disaster was the implementation of a new state-of-the-art Emergency Operations Centre (EOC) after the results of the 2005 flood. The EOC contains approximately 25 staff daily and can operate as a self-contained facility for the critical first 72 hours of an emergency. Key personnel from City business units and external agencies like electrical, gas, and health services can assemble in the EOC in order to support front-line response personnel and business continuity. There is a Geographic Information System that includes maps with embedded information, live feeds from City traffic, and police helicopter cameras (Calgary.ca). Since 2005, CEMA conducts a corporate Hazard Identification and Risk Assessment (HIRA) each year. HIRA identified Calgary as having a high probability and high impact of risk of flooding, subsequently, smart reservoir management reduced the peak flow rate from a one in 500-year event to a one in 100 -year event. Business units implemented 74 improvements to flood mitigation strategies to reduce the impact on citizens, businesses, and infrastructure. This helped to increase preparedness and response specifically to flood disasters. Furthermore, the improvements reduced damage, allowed more time and accuracy for evacuations, enhanced emergency response and recovery co-ordination (EM2013-0822).

CEMA's additional strategies were maintaining a state of preparedness by refining roles, responsibilities, and communication. Training and educating 312 staff members through mock disasters, and monitoring flood conditions through forecasts. Sandbags, flood tubes, and 16 temporary berms were placed throughout the city to help divert water to protect communities and infrastructure. During response CEMA made public safety a priority by initiating evacuations using inundation maps and plans were developed in the EOC to conduct staged de-energising of communities. Military and firefighters from neighbouring cities were called in for additional assistance to response. Maintaining and preserving communications lines was critical during the response phase, 9-1-1 emergency lines remained open and 3-1-1 service lines were saved by a back-up system, which allowed the handling of 100,000 calls. Over 140 media releases were delivered to keep citizens up-to-date, however, the city's website crashed after encountering 1.1 million visits (EM2013-0822).

\subsubsection{Social Impact and Strategic Management of the Event}

The impact of the 2013 flood resulted in the evacuation of over 80,000 Calgarians in over 20 communities as well as 160 animals from the Calgary Zoo, and 600 people were rescued from the water and roof tops (YouTube 2014). Unfortunately, thousands of people have lost personal belongings and the disaster took one life of a Calgarian and four deaths in total in Southern Alberta (Livingstone 2013). People who knew where to get support for their issues 
had nowhere to go because the city was shut down (YouTube 2013). However, the flood disaster developed pride in the community. Organizations such as United Way, Red cross, police officers, firefighters, and thousands of volunteers helped those in need. Economically the cost of the floods, according to the Alberta Minister of Finance, was in the range of five to six billion dollars and the cost of infrastructure repair alone was an estimated $\$ 400$ million dollars (YouTube 2013). The provincial government immediately approved $\$ 1$ billion in spending for the first phase of emergency recovery (CBC News 2013). Environmentally, John Pomeroy a top researcher in water resources and climate change at the University of Saskatchewan, says the natural disaster has permanently transformed how the landscape will handle future flooding and climate change models predict heavier rains which favours more flooding in the future (Weber, 2013).

\subsection{Montrose, Scotland. 2016.}

In 2016 the rainfall over the county of Angus, Scotland rose to severe levels as the UK encountered one of the wettest winters for over 100 years due to Storm Frank (The Courier 2015). The town of Montrose is built on a sandbank on the coast and has two rivers that begin up in the Glens and meet the sea at either side of Montrose. As stated in the Angus Council Communities Committee report "during December 2015, relentless heavy rainfall impacted on Angus, the worst of which was experienced on 30 December 2015 as part of Storm Frank, 4 January 2016 and 7 January 2016. The rainfall created significant issues over a number of weeks, with saturated ground, surface water flooding and rivers reacting to the volume of water" Angus Council 2016, page 1). It was reported in the media that the total "cost of the emergency response to Storm Frank in Angus has been tallied at $£ 1.4$ million" (The Courier 2016).

\subsubsection{Risk Perception of the Event}

The rivers North Esk and South Esk have flooded before, with local landowners being quite used to where floods may arise, but it was the unusual volume of rainfall experienced that made these floods a rare event. The Scottish Environmental Protection Agency (SEPA) are the flood warning authority for Scotland and have 250 rainfall, river and coastal stations that monitor the potential flood risks; by combining this data with meteorological data from the Met Office they form the Scottish Flood Forecasting Service (SEPA 2017a). During the 2016 floods SEPA issued "more than 35 flood warnings in the Grampian, Moray, Angus, Tayside and Scottish Borders regions" (STV News 2016, below second image). There was one previous significant flood on the river North Esk in November 2002, with a flow rate that was the highest the station had recorded since it began in 1983, led to the evacuation of residents from Marykirk and Logie (SEPA 2017b). In contrast the river South Esk, at Montrose Basin, has only experienced one coastal flood due to a high tide event in 2005 since recording began (SEPA 2017c).

\subsubsection{Flood Risk Management Strategy}

Under the legislation of the Flood Risk Management (Scotland) Act 2009 SEPA is the responsible agency in Scotland for developing and delivering flood management strategies 
having conducted a National Flood Risk Assessment in 2011 as part of this legislation (SEPA 2017b). Under the legislation SEPA co-ordinate with outside partners, such as the Met Office, Local Authorities, Scottish Water and Scottish Natural Heritage, to deliver flood warnings, advice and strategies for reducing the risks of such events (SEPA 2017c). Due to the political boundaries in Scotland the town of Montrose is located at the northern boundary of the county of Angus with areas to the north of the river North Esk being part of Aberdeenshire South so both Local Authorities had to co-ordinate to respond to the same event. Under the strategy Montrose and its surrounding villages and landowners is part of two potentially vulnerable areas (PVA), designated 07/03 and 07/04, with SEPA having outlined the risks and strategies for each of these areas. In area 07/04, the Tay Estuary and Montrose Basin area, Angus Council are the solely responsible Local Authority but in area 07/03 the responsibility is shared between Angus Council and Aberdeenshire Council (SEPA 2017b, SEPA 2017c).

In the flood management strategy documents produced by SEPA for PVA 07/03 and 07/04 they describe the flood management strategies that were to be used for each area. Within the 07/03 area the highest risks "are to residential properties followed by damages to non-residential properties. The Dundee to Aberdeen railway line is also notably impacted" (SEPA 2017b, page 41). Due to the experiences of having previously flooded the strategy proposed by SEPA involves learning more about flood risks in the area stating "SEPA will seek to incorporate additional surface water data into the flood maps to improve understanding of flood risk. Approximately $1,100 \mathrm{~km}^{2}$ of improved surface water data is currently available within this Local Plan District" (SEPA 2017b, page 46) and "continue to maintain the Inchbare, Marykirk and the Logie Mill and Craigo flood warning areas which are part of the North Esk river flood warning scheme" (SEPA 2017b, page 47). Conversely in area $07 / 04$ the low history of flooding meant the strategies were less developed and focused more on reducing flood risks, with this involving engaging with stakeholders as stated in the report "SEPA will engage with local authorities and community resilience groups where possible. Local authorities will be undertaking additional awareness raising activities" (SEPA 2017c, page 61).

Just prior to the event SEPA and the Met Office issued separate warnings regarding the forecast rainfall from Storm Frank in line with the proposed flood forecasting warning strategy. As the flood developed "Angus council staff, along with our emergency service partners, other agencies and volunteers, worked long hours in challenging conditions to help those who felt the greatest impact of Storm Frank" (Brechin Advertiser 2016a, last paragraph) and in the days after the floods "our staff were also out in force in those areas affected by (the) flooding to assess the on-going situation and identify any issues" (Brechin Advertiser 2016a, last paragraph). The sports centre in Montrose was used as a temporary shelter for displaced residents with local residents phoning Angus Council offering goods to assist those who had been affected with Angus Council stating "the support both offered and given was very much appreciated" (Brechin Advertiser 2016a, last paragraph).

\subsubsection{Social Impact and Strategic Management of the Event}

For the Montrose area the largest amount of disruption suffered was to travel as the railway 
line between Dundee and Aberdeen was closed due to the flooding at the North Esk portion of the line, on top of this surface water retention forced the closure of the three major roads leading to Montrose to everyone but services responding to the flood. Residents were evacuated from the Craigo, Logie Mill and Marykirk areas of the North Esk as the rivers burst their banks and were taken to the rest centre at Montrose Sports Centre (Brechin Advertiser 2016b). Although the management of the flood event had reduced the impact where possible it was reported that Angus Council would be looking at a total cost of $£ 1.4$ Million for the response and necessary repairs, The Scottish Government declared it would offer financial relief for local authorities through the Bellwin Scheme (The Courier 2016).

\section{Discussion and Comparison of Cases}

It is clear from the summaries of the events provided that both of the events were of an unusual nature; however it is expected that such events may occur more frequently as rainfall increases due to climate change. This rise in the risk of pluvial flooding has increased the need for research to understand how to best manage flood risks and develop flood management strategies. The review of the existing research literature highlighted how the perceptions of flood risk can be shaped by organisations and Government so the perceptions of the communities from the case studies were compared of before the events occurred.

In Calgary, Canada the residents were caught relatively unaware by the severity of the event. This may have been affected by the perception that the rainfall in June is normal causing the residents to underestimate the potential risk. Although there is mention of reservoir management there is no data in the case available to determine whether there was a flood forecasting warning system in place in the area. This may have helped the community to prepare better and implement flood management strategies before the event struck which may have reduced the impact of the event. In Montrose, Scotland there was a division in perceptions; the communities around the North Esk river area had experienced flooding previously, and were a known risk area that was being monitored by SEPA, but the Montrose Basin area was anticipated to be more at risk from coastal flooding and therefore perceptions of pluvial flooding were very low. In contrast to Calgary there is data available for Montrose to show that monitoring was in place, and warnings issued, prior to the event. This vastly increased the speed of the response with the most affected areas being known in advance and allowed for the community to prepare as necessary.

The strategy of Calgary had been developed after the experiences of the previous floods in 2005, where revisions were made to the existing strategies of the time and investment made in infrastructure improvements. A large part of this reaction was the introduction of the Emergency Operations Centre (EOC) to oversee the flood management; this centre monitors the situation and allows for key personnel from various agencies to gather to deal with the flood. The strategy for Montrose was more proactive and based largely on the Scottish Flood Forecasting Service, jointly offered by SEPA and the Met Office, and their ability to monitor the flood risks and issue warnings where required in advance of the events. Due to the more reactive nature of Calgary's strategy, and low risk perceptions of the incoming flood, there 
was more impact before the state of emergency was declared than in Montrose.

The social impact of the pluvial flood events would appear to show a good deal of resilience in both of the communities; however the scale of the event in Calgary was noticeably larger due to the scale of the urban environment. With a projected cost of up to \$6 Billion Canadian dollars, 80,000 citizens evacuated, 160 animals from the city's zoo and one recorded death compared to the $£ 1.4$ Million cost and less than 100 evacuations in a mostly rural area of Montrose shows the difference in scale of the impact. It can be deduced that the costs may have been higher in Montrose area if the event had not been well predicted and warnings issued. In both cases it took the co-ordination of multiple stakeholders working together to manage both of the events and suggests that so long as they are working towards common goals this does not appear to hamper the management of flood risks.

From the comparison of the flood management strategies, and the social context, of each of these pluvial flood events it is clear that having a good understanding of the potential risks is necessary for the development of effective flood management strategies. This allows for the stakeholders of the community to be informed about the risks so they can assist in the development of strategies too and know when the risks are likely to occur therefore the development of a proactive system, like the Scottish Flood Forecasting Service, to monitor and warn of potential risks is recommended. It is clear from the case studies that due to the low risk perceptions in Calgary less was done to prepare for the floods and this may have lessened the impact for the residents of the city if warnings had been issued prior. It is also clear that the involvement of multiple agencies is necessary to an effective flood management strategy; both cases demonstrate the co-ordination of multiple stakeholders working to common goals can be greatly successful for flood management.

\section{Conclusion}

This research was responding to the calls of other researchers into the wider social context of pluvial flood events and demonstrates that this area is of significant importance for further research; it has also demonstrated the suitability of using case study research for this topic. The case studies allowed for the examination of the social context to determine how it can affect the development and implementation of flood management strategies and the cases demonstrated that there was the co-ordinated involvement of multiple agencies in the strategies used in both events.

It was shown in the analysis of the case studies that there is a constant need for monitoring so warnings can be issued before an event happens to lessen the potential impacts, the perceptions of the risks are not always high in the community due to the low probability of such pluvial floods, therefore this is an important point for future researchers and policy developers to examine. Does the prediction of a pluvial flood event reduce the impact or are they always going to be dynamic events with varying impacts? It is also demonstrated that there needs to be a co-ordinated response as part of the flood management strategy in order to prioritise needs and send assistance to where it is most required first however it is important 
to note that they need to have a common set of goals in order to be effective. Therefore when developing strategies it is important to assess the potential risks, identify the likely places to be affected, engage with the stakeholders of the community and monitor the environmental conditions.

Another point that is highlighted by this research is the need for increased awareness of the rise in the likelihood of future pluvial events as increased rainfall is a consequence of climate change. For policy developers this could mean revising their current strategies to ensure they can cope with unusual weather and unexpected rainfall levels, as well as increasing awareness amongst the community and inform them of the risks, engage with them on consultations and encourage them to form their own flood action groups to improve resilience. This research has shown that there was vast improvement in the response rate in Montrose due to their having been monitoring and forecasting in place by the joint efforts of the agencies responsible for monitoring the weather and flood risks; this proactive stance may have been significant in the speed of the response and the reduction of the financial impact overall but there was insufficient data available to examine this point further in this research study therefore this will need to be examined by future researchers.

\section{References}

Angus Council. (2016). Weather and flooding events; December 2015 and January 2016: Report by Head of Technical and Property Services. Retrieved 19 ${ }^{\text {th }}$ January 2017 from: http://www.angus.gov.uk/download/meetings/id/2060/agenda_item_no_6___report_no_ 8316_-_weather_and_flooding_events_december_2015_and_january_2016

Birkholz, S., Muro, M., Jeffrey, P., \& Smith, H.M. (2014). Rethinking the relationship between flood risk perception and flood management. Science of the Total Environment, 478, 12-20. https://doi.org/10.1016/j.scitotenv.2014.01.061

Brechin Advertiser. (2016a). Aerial footage of Angus and Mearns flooding the day after Storm Frank. Retrieved $19^{\text {th }}$ January 2017 from: http://www.brechinadvertiser.co.uk/news/videoaerialfootageofangusandmearnsfloodingt hedayafterstormfrank13989126

Brechin Advertiser. (2016b). Storm Frank hits Angus. Retrieved 19 $9^{\text {th }}$ January 2017 from: http://www.brechinadvertiser.co.uk/news/videostormfrankhitsangus13987892

Brudler, S., Arnbjerg-Nielsen, K.A., \& Hauschild, M.Z. (2016). Life cycle assessment of stormwater management in the context of climate change adaptation. Water Research, 106, 394-404. https://doi.org/10.1016/j.watres.2016.10.024

Calgary.ca. (2016). Emergency Operations Centre. Retrieved $16^{\text {th }} 2017$ from: http://www.calgary.ca/CSPS/cema/Pages/The-Emergency-Operations-Centre.aspx

CBC News. (2013). Calgary Floods to cost Economy Billions: Businesses, workers both take $a$ hit from disaster. Retrieved $16^{\text {th }}$ January 2017 from: 
http://www.cbc.ca/news/canada/calgary/calgary-floods-to-cost-economy-billions-1.1365 207

Collis, J., \& Hussey, R. (2009). Business research: a practical guide for undergraduate and postgraduate students ( ${ }^{\text {rd }}$ Ed.). Palgrave: McMillan.

EM2013-0822. (2013). Summary of June 2013 Flood Emergency Response and Initial Recovery Efforts. Retrieved $16^{\text {th }}$ January 2017 from: file://C:/Users/hocke/Downloads/22046412062013071655421.pdf

Floodstory. (2014). Calgary grinds to a halt: June 2005. Retrieved $16^{\text {th }}$ January 2017 from: http://floodstory.com/floods/2005-flood

Kajenthira, A., Holmes, J., \& McDonnell, R. (2010). The role of qualitative risk assessment in environmental management: A Kazakhstani case study. Science of the Total Environment, 420, 24-32. https://doi.org/10.1016/j.scitotenv.2011.12.063

Kenyon, W. (2007). Evaluating flood risk management options in Scotland: A participant-led multi-criteria approach. Ecological Economics, 64, 70-81. https://doi.org/10.1016/j.ecolecon.2007.06.011

Livingstone, A. (2013). Alberta floods: Assessing the human, environmental and economic impacts. $\quad$ Retrieved $16^{\text {th }} \quad$ January 2017 from https://www.thestar.com/news/canada/2013/06/24/alberta_floods_assessing_the_human _environmental_and_economic_impacts.html

Mann, C., \& Wolfe, S.E. (2016). Risk Perceptions and Terror Management Theory: Assessing Public Responses to Urban Flooding in Toronto, Canada. Water Resource Management, 30, 2651-2670. https://doi.org/10.1007/s11269-016-1308-8

Nielson, N. (2015). Flood 2013: when leaders emerged and risk management evolved at the University of Calgary. Risk Management \& Insurance Review, 18(1), 143-159. https://doi.org/10.1111/rmir.12035

Rambaruth, P. (2012). Rethinking the Case Study in International Business and Management Research. Journal of Teaching in International Business, 23(3), 251-255. https://doi.org/10.1080/08975930.2012.744636

Rouillard, J.J., Ball, T., Heal, K.V., \& Reeves, A.D. (2015). Policy implementation of catchment-scale flood risk management: Learning from Scotland and England. $\begin{array}{lllll}\text { Environmental Science } \quad \& \quad \text { Policy, } & \text { 50, }\end{array}$ https://doi.org/10.1016/j.envsci.2015.02.009

Saunders, M., Lewis, P., \& Thornhill, A. (2009). Research methods for business students $\left(5^{\text {th }}\right.$ Ed.). Essex: Pearson.

SEPA. (2017a). Forecasting flooding. Retrieved $19^{\text {th }}$ January 2017 from: https://www.sepa.org.uk/environment/water/flooding/forecastingflooding/

SEPA. (2017b). North of Brechin (Potentially Vulnerable Area 07/03). Retrieved $19^{\text {th }}$ 
http://apps.sepa.org.uk/FRMStrategies/pdf/pva/PVA_07_03_Full.pdf

SEPA. (2017c). Montrose Basin (Potentially Vulnerable Area 07/04). Retrieved $19^{\text {th }}$ January 2017 from: http://apps.sepa.org.uk/FRMStrategies/pdf/pva/PVA_07_04_Full.pdf

Shao-Hong, W., Tao, P., \& Shan-Feng, H.E. (2012). Climate Change Risk Research: A Case Study on Flood Disaster Risk in China. Advances in Climate Change Research, 3(2), 92-98. https://doi.org/10.3724/SP.J.1248.2012.00092

STV News. (2016). Further flooding alert as heavy rain hits Scotland after Storm Frank. Retrieved $\quad 3^{\text {rd }} \quad$ January 2017 from: https://stv.tv/news/north/1337862floodwarningsasheavyrainbattersscotlandinwakeofstor mfrank/

The Courier. (2015). Storm Frank brings serious flooding in Perthshire and Angus. Retrieved $12^{\text {th }} \quad$ January 2017 from: https://www.thecourier.co.uk/news/scotland/242045/stormfrankbringsseriousfloodinginp erthshireandangus/

The Courier. (2016). Storm Frank response hits Angus Council with $£ 1.4$ million bill. Retrieved $12^{\text {th }} \quad$ January 2017 from: https://www.thecourier.co.uk/news/local/angusmearns/246123/stormfrankresponsehitsan guscouncilwith14millionbill/

Weber, B. (2013). Alberta Floods Have Changed The Rockies Forever, Says Scientist. Retrieved $16^{\text {th }} \quad$ January 2017 from: http://www.huffingtonpost.ca/2013/06/24/alberta-floods-rockies-damage_n_3492115.ht $\mathrm{ml}$

Whitfield, P.H., \& Pomeroy, J.W. (2016). Changes to flood peaks of a mountain river: implications for analysis of the 2013 flood in the Upper Bow River, Canada. Hydrological Processes, 30, 4657-4673. https://doi.org/10.1002/hyp.10957

Woodside, A.G. (2010). Case study research: theory methods practice. $1^{\text {st }}$ Ed. Bingley: Emerald.

YouTube. (2013). The Aftermath: Southern Alberta Flood 2013. Retrieved $13^{\text {th }}$ January 2017 from: https://www.youtube.com/watch?v=PLGvrTGspv4

YouTube. (2014). 48 Hours of Water - CBC Short Documentary - Alberta Flood 2013. Retrieved 13th January 2017 from: https://www.youtube.com/watch?v=RBLZyolbvts

\section{Copyright Disclaimer}

Copyright for this article is retained by the author(s), with first publication rights granted to the journal.

This is an open-access article distributed under the terms and conditions of the Creative Commons Attribution license (http://creativecommons.org/licenses/by/3.0/). 